\title{
Molecular Phylogenetics of Hepatitis D Virus in New Zealand and the Implications for Pacific Island Countries
}

\author{
Kathy Jackson ${ }^{a}$ Margaret Littlejohn ${ }^{a}$ Ed Gane ${ }^{b}$ Stephen Locarnini ${ }^{a}$ \\ aResearch and Molecular Development and WHO Regional Reference Laboratory for Hepatitis B/D, Victorian \\ Infectious Diseases Reference Laboratory, Royal Melbourne Hospital, Doherty Institute for Infection and Immunity, \\ Melbourne, VIC, Australia; 'bepartment of Medicine, University of Auckland and New Zealand Liver Transplant Unit, \\ Auckland City Hospital, Auckland, New Zealand
}

\section{Keywords}

Hepatitis delta virus · New Zealand · Pacific Islands ·

Phylogenetics

\begin{abstract}
Hepatitis delta virus (HDV) is considered a satellite virus that requires hepatitis $B$ virus surface antigen for infectivity. HDV is endemic in some Pacific Island (PI) countries, including Kiribati and Nauru, with a unique genotype 1, "Pacific clade." The aims of this study were to determine the HDV genotypes in New Zealand and investigate the link of strains to other PI countries and the rest of the world through phylogenetics. Sequencing and phylogenetic analyses were performed on 16 HDV-positive serum samples from 14 individuals collected between 2009 and 2014 at Auckland Hospital. Thirteen of 14 strains were confirmed as genotype 1 and 1 was genotype 5. Eleven of the 13 genotype 1 strains clustered with the Pacific clade. These were isolated from subjects born in Samoa, Kiribati, Tuvalu, and Niue. Another genotype 1 strain isolated from a Maori health-care worker clustered most closely with a European strain. There was an African genotype 1 and genotype 5 from African-born subjects with HIV coinfection. This study supports the probable transmission of HDV Pacific
\end{abstract}

clade around the PI from Micronesia to Polynesia. The data also confirm the need to screen hepatitis B surface antigenpositive individuals for HDV.

(c) 2021 S. Karger AG, Basel

\section{Introduction}

Hepatitis delta virus (HDV) is a small incomplete human hepatotropic virus that requires hepatitis $B$ virus (HBV) surface antigen (HBsAg) for assembly, release from the infected cell, and infectivity [1]. HDV infects 2-8\% HBsAg carriers [2] or 15-20 million people worldwide [3]. Recent publications, however, estimate that this may be closer to 48-72 million persons as it is largely underdiagnosed $[4,5]$. HBV/HDV coinfection causes the most severe forms of viral hepatitis with increased risk of cirrhosis, hepatic decompensation, hepatocellular carcinoma, and fulminant hepatitis [2, 6-9].

$\mathrm{HDV}$ is transmitted by the parenteral route and may be acquired as a coinfection, simultaneous exposure/infection of HBV and HDV, or superinfection where an individual with an established HBV infection is exposed to HDV. Superinfections are more likely to develop into

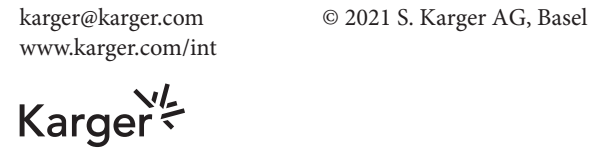


Table 1. Clinical and epidemiological data of the patients and strains analysed

\begin{tabular}{|c|c|c|c|c|c|c|c|}
\hline Patient/sample & $\begin{array}{l}\text { Patient } \\
\text { age, years }\end{array}$ & Gender & $\begin{array}{l}\text { Country of birth/ } \\
\text { ethnicity }\end{array}$ & $\begin{array}{l}\text { Sample year of } \\
\text { collection }\end{array}$ & $\begin{array}{l}\text { HDV } \\
\text { genotype }\end{array}$ & Clade & Clinical notes \\
\hline S1 & 70 & $\mathrm{~F}$ & Samoa & 2014 & 1 & Pacific & Cirrhosis at diagnosis, terminal HCC \\
\hline S2 & 27 & M & Other Pacific peoples & 2014 & 1 & Pacific & \\
\hline S3 (duplicate = S8) & 47 & M & Liberia & 2013 & 5 & African & HIV coinfection, mild fibrosis \\
\hline S5 $($ duplicate = S9) & 36 & $\mathrm{~F}$ & Ethiopia & 2013 & 1 & African & HIV coinfection, cirrhosis \\
\hline S6 & 49 & M & Tuvalu & 2013 & 1 & Pacific & Cirrhosis at diagnosis, developed HCC \\
\hline S7 & 57 & $\mathrm{~F}$ & Maori & 2012 & 1 & European & $\begin{array}{l}\text { Cirrhosis at diagnosis, developed } \\
\text { decomposition, eventually transplanted }\end{array}$ \\
\hline S10 & 20 & M & Kiribati & 2013 & 1 & Pacific & Cirrhosis at diagnosis \\
\hline S13 & 42 & M & Samoan & 2012 & 1 & Pacific & Mid fibrosis \\
\hline S14 & 57 & M & Samoan & 2012 & 1 & Pacific & Mid fibrosis \\
\hline S15 & 65 & M & Niue & 2011 & 1 & Pacific & Cirrhosis at diagnosis, died from HCC 2012 \\
\hline S16 & 23 & M & Kiribati & 2009 & 1 & Pacific & Mid fibrosis \\
\hline
\end{tabular}

HCC, hepatocellular carcinoma; HDV, hepatitis delta virus.

chronic HBV/HDV. The incubation period ranges from weeks to months, and the infection may present clinically as a worsening of hepatitis symptoms. Exposure to HDV is determined by antibody detection; however, HDV RNA detection in serum confirms current infection [10]. Until recently, HDV treatment has relied on administration of interferon-alpha but with limited success [11, 12]. Newer therapies are in development and should be available soon. Entry inhibitors such as bulevirtide, prenylation inhibitors such as lonafarnib, and capsid inhibitors are in clinical trials and should provide a more targeted sustained response [12].

HDV is found universally and with endemic pockets in Central and West Africa, northern Asia, Middle East, eastern Europe, Amazon Basin, and the Pacific Islands (PIs) [13-15]. Mongolia has an extremely high prevalence with a reported $6.7 \%$ blood donors and $56.5 \%$ of patients with chronic hepatitis with detectable HDV RNA [16]. There are $8 \mathrm{HDV}$ genotypes, $1-8$, which have up to $40 \%$ divergence in nucleotide sequence of the genome $[17,18]$.

The incidence of HDV in New Zealand (NZ) has not been documented recently, but a past report suggested that around $6.7 \%$ of HBsAg-positive subjects in Auckland had antibodies to HDV (anti-HDV) and that $61 \%$ of these were from the PI of Samoa [19]. NZ and Samoa are located in Polynesia, 1 of the 3 regions of the PIs. Polynesia also incorporates Hawaii, Tonga, Tuvalu, and Tokelau. Melanesia incorporates Papua New Guinea, Solomon Islands, Fiji, Vanuatu, and New Caledonia, while Micronesia includes Kiribati, Nauru, Guam, and Marshall Islands. There is historical serological evidence of HDV in the PIs implicating all 3 regions including Solomon Islands, Marshall Islands, and Niue $[20,21]$. However, a paucity of recent publications and testing for current infection with HDV RNA assays precludes an assessment of the true prevalence in these PIs, with the exception of Kiribati. Studies from Kiribati have revealed a unique clonally derived subtype of HDV genotype 1, the Pacific clade, which infects up to $37.5-41 \% \mathrm{HBsAg}$-positive individuals in this small Micronesian country [14, 15]. A previous study documented the presence of this Pacific clade in Australia [22]. Thus, the aims of this study were to determine the HDV genotypes in NZ and investigate the link of strains to other PI countries and the world through phylogenetics. 


\section{Materials and Methods}

Sixteen serum samples from 14 individuals collected between 2009 and 2014 at Auckland Hospital were coded and sent to the WHO Regional Reference for HBV and HDV, Melbourne, for sequencing, genotyping, and phylogenetic analysis. The method used has been described previously $[14,22]$ and is summarized here. RNA was extracted and a 420-bp product of the HDV delta antigen was amplified, purified, and sequenced. Sequences were aligned with $66 \mathrm{HDV}$ sequences from GenBank [23], 7 sequences isolated from Kiribati samples and 8 representative sequences isolated from Australian samples [11] using MAFFT [24] and then manually corrected using BioEdit v7.0.5 [25]. Phylogenetic analyses were performed based on the maximum likelihood phylogenetic tree generated using the GTR + G + I substitution model, with 1,000 bootstrap replicates using MEGA5 [26].

\section{Results}

Clinical and epidemiological data are summarized in Table 1. Eight of the 14 patients had cirrhosis, and there were 2 patients with HIV coinfection. Strains from 13 of 14 subjects were identified as genotype 1; the remaining 1 (S3) was genotype 5, an African genotype. Phylogenetic analysis shown in Figure 1 revealed that 11 of the genotype 1 strains clustered with the unique Pacific clade originally identified in Kiribati and Nauru [14, 15, 22]. These 11 NZ strains were from subjects born in Kiribati or another PI (Samoa, Tuvalu, or Niue). The S5 genotype 1 strain, isolated from an individual born in Ethiopia, clustered with African genotype 1 strains. S7, isolated from a Maori NZ health-care worker who acquired HDV after occupational exposure, clustered with other genotype 1 strains. The closest match, with $94 \%$ similarity was with an Italian strain. Figure 2 shows a map of the PIs where there is serological evidence of HDV and direct or indirect current $\mathrm{HDV}$ infection, as revealed by Australian [22] and NZ isolates.

Fig. 1. A maximum likelihood phylogenetic tree showing the inferred relationship between the genotype 1 and 5 sequences isolated from this study and HDV sequences of known genotype retrieved from GenBank (363 nt). Accession numbers and country of origin of the sequences downloaded from GenBank are indicated on the tree. Support values for the branches $>60 \%$ are indicated. The HDV sequences from this study are marked in red, and strains from Kiribati within the Pacific clade are highlighted in pink. Representative samples previously described from Australia [11] are marked in blue. CAR, Central African Republic; HDV, hepatitis delta virus.

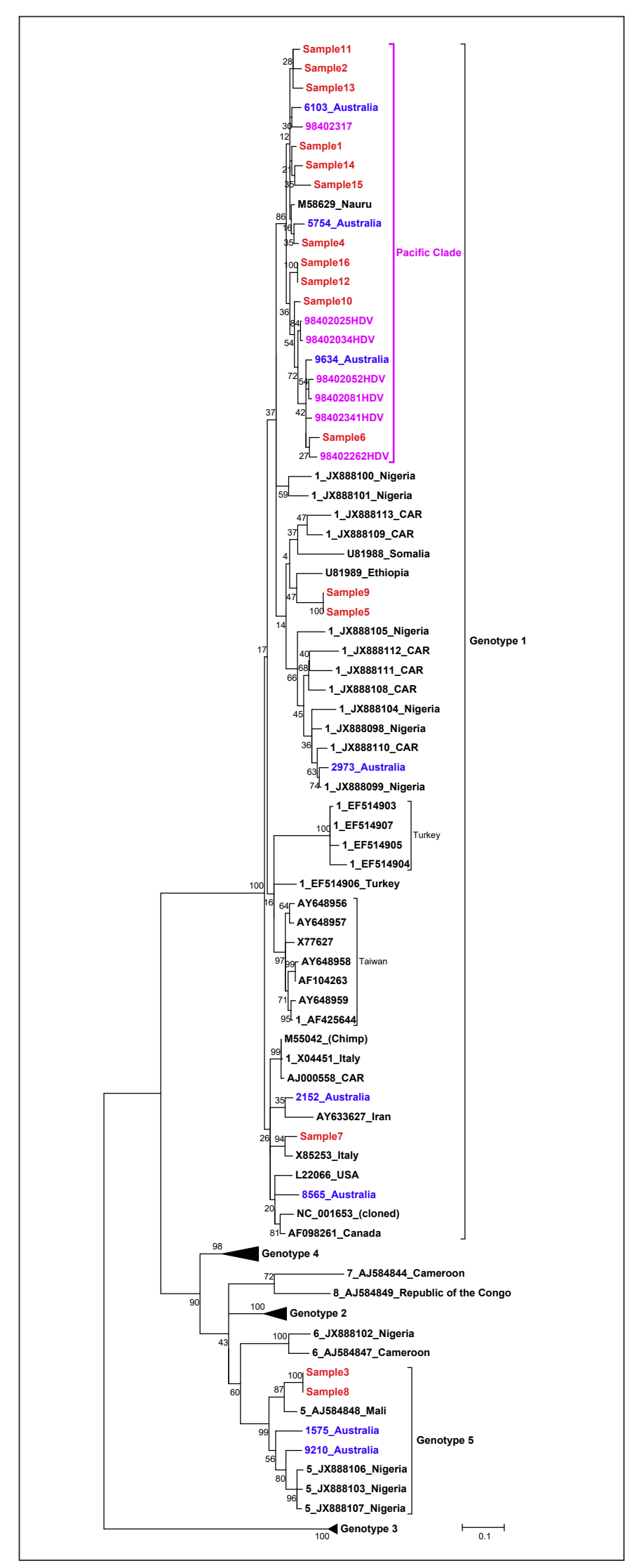

Jackson/Littlejohn/Gane/Locarnini 
Fig. 2. Map of the Pacific Islands highlighting countries/territories with HDV RNA evidence, serological evidence of HDV infection, and/or indirect HDV RNA evidence (HDV RNA detected in NZ from PIborn peoples). Areas with low serological evidence have been tested and shown to have little exposure to HDV. Status of HDV is largely unknown in un-highlighted countries/islands. NZ, New Zealand; PI, Pacific Island; HDV, hepatitis delta virus.

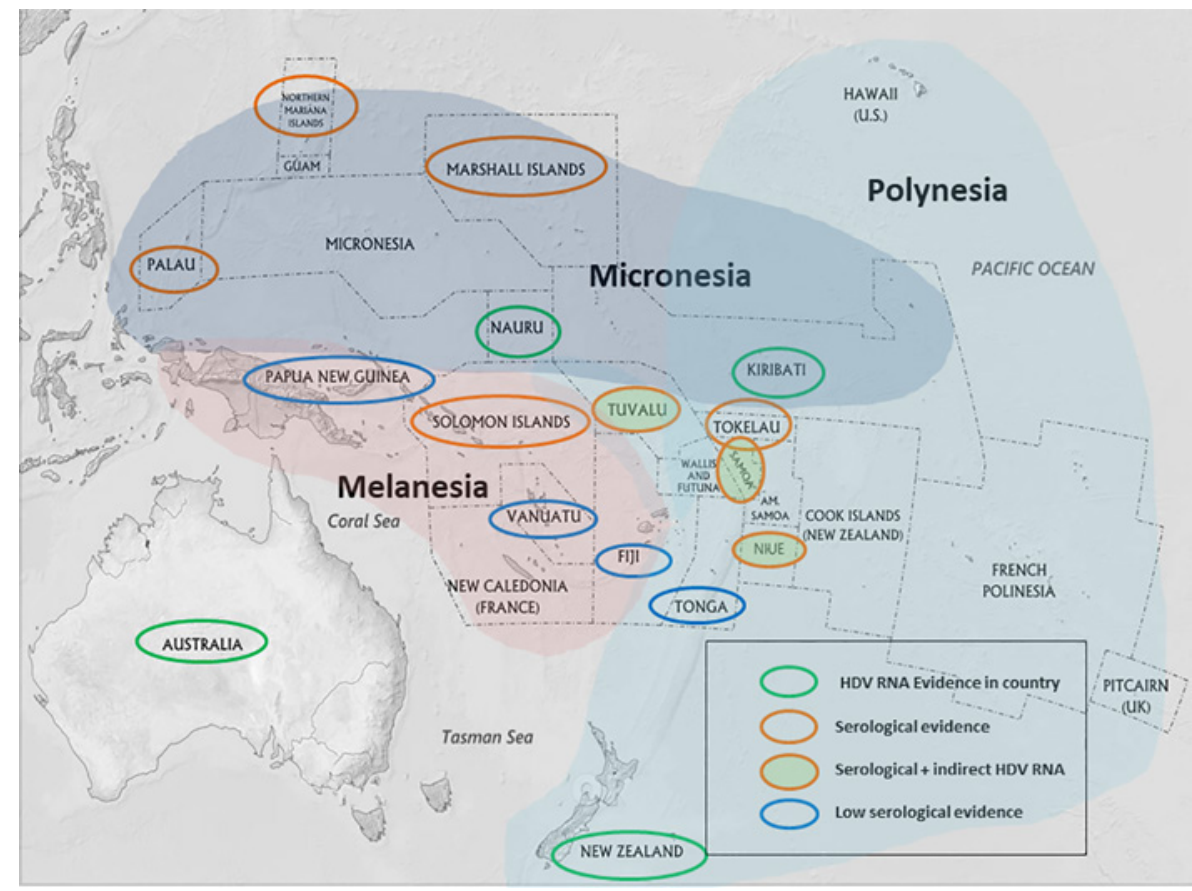

\section{Discussion}

This study describes the HDV strains circulating in NZ which has a relatively low prevalence of HDV in NZ-born Maoris and Europeans and a high prevalence in those of Samoan origin [19, 27]. HDV viraemia was identified in 3 Samoans, and the HDV isolated was confirmed to belong to the Pacific strain (shown in Table 1; Fig. 1). Indeed, there were 11 individuals described here with the Pacific strain, which confirms the presence outside of the endemic Micronesian islands of Kiribati and Nauru [14, 28-31]. Although transmission within NZ is possible, transmission between the PIs before arriving in NZ is more likely with accumulating evidence of the Pacific strain in individuals from the Polynesian islands of Tuvalu (S6) and Niue (S15), as well as Samoa (S1, S13, and S14). This indirectly supports the historical serological evidence of HDV in these PIs depicted in Figure 2. Recent estimates suggest HDV prevalence in Samoa may be as high as $20 \%$ HBsAg-positive individuals (personal communication).

A study by Han et al. [14] reported an absence of HDV markers in Fiji, Vanuatu, and Tonga. A recent study in Australia confirmed the Pacific strain in an individual born in Fiji [22]. Fiji has historically low serological evidence of HDV [32] and is unlikely to be endemic. The sporadic presence of HDV in the Pacific (Fig. 2) reflects its irregular prevalence in the world. There are certainly endemic pockets with HDV viraemia confirmed in Kiribati at $41 \% \mathrm{HBsAg}$-positive individuals [15] and highly suspected in Nauru, where contract workers from Kiribati may have been implicated in the introduction of HDV [33]. There is also now circumstantial evidence of HDV infection in Samoa, Tuvalu, and potentially Niue, although the incidence of HDV in Niueans living in NZ appears to be very low. Serological evidence shown in Figure 1 suggests that HDV infection may be even more widespread in the PIs than originally thought. This is not surprising as there is considerable movement between the Pacific nations for trade, exploration, social, and economic reasons. Tattooing, piercings, and unhygienic dental practices may also play a role in the transmission of HDV in this region $[15,28]$.

The potential origin of the Pacific HDV strain has been discussed previously $[14,15]$. The strain shares a common ancestor with African and Turkish HDV strains (Fig. 1) yet is clearly distinct from these and other genotype 1's. The PIs were exposed to European colonization at different times in history, offering a hypothetical source of introduction. However, the delta strains from Europe also do not cluster with the PI strain. An alternative plausible theory is that there was a point introduction into Kiribati and the cultural practices at the time favoured transmission and establishment of endemicity. Almost half the population on Kiribati were refugees from Samoa, and this may explain the similarly high endemicity 
in Samoans. The authors are hopeful that future studies using molecular clock analyses may enable the age of the Pacific strain to be determined and provide a clue on the time and source into the PIs.

There is certainly a need to investigate the HDV prevalence further in other PI countries such as Niue, the Solomon Islands, Palau, Tokelau, and the Marshall Islands, where there is strong HDV serological evidence [34] and $\mathrm{HBV}$ infection is endemic. Investigations in Papua New Guinea are also needed as Brindle et al. [34] detected HDV antibody in 1 of 3 HBsAg-positive samples in 1987. The authors have detected 1 antibody-positive (HDV RNA-negative) sample in $50 \mathrm{HBsAg}$-positive samples from Popondetta (PNG) in 2019 (data not shown).

A previous study has shown that African genotype 1 strains tend to originate from East Africa such as Sudan and Egypt and genotype 5 strains from West Africa including Liberia and Sierra Leone [22]. This view was supported in this study where HDV genotype 5 was isolated from a Liberian-born patient (S3) and the African genotype 1 from an Ethiopian-born patient (S5). It is also interesting to note that the 2 African-born patients in NZ were also coinfected with HIV. A recent study in Nigeria reported that triple infection with $\mathrm{HIV} / \mathrm{HBV} / \mathrm{HDV}$ is rare but can occur at an incidence of around $0.7 \%$ [35]. This was confirmed by studies carried out in Uganda [36] and the USA where $2.2 \%$ of HBV/HIV coinfected subjects had HDV RNA detected [37].

The clinical history in Table 1 documents the severity of $\mathrm{HBV} / \mathrm{HDV}$ coinfection with 8 of 14 subjects having cirrhosis and 3 developing hepatocellular carcinoma. The severity of disease reiterates the necessity of diagnosing HDV coinfection, particularly as antiviral treatment becomes available [38]. It is recommended that all HBsAgpositive individuals are screened for HDV, particularly those from the PIs and Africa.
This study reveals the presence of European and African HDV genotypes in NZ and confirms probable transmission of HDV Pacific clade throughout the PIs from Micronesia to Polynesia. Further studies are warranted to assess the prevalence in other PIs in order to provide appropriate clinical management and target the prevention of the ongoing transmission of this serious and often neglected infection.

\section{Acknowledgements}

The authors would like to acknowledge Dr. Lilly Yuen for assistance with Figure 2 and Dr. Fahimeh Rahnama for providing the samples.

\section{Statement of Ethics}

Ethical approval was provided by the Auckland District Health Board and not subject to an external Ethics Committee. Patient consent was waived as the work was considered to be important for the public health of NZ.

\section{Conflict of Interest Statement}

The authors declare that there are no conflicts of interest.

\section{Funding Sources}

The authors did not receive any funding.

\section{Author Contributions}

Kathy Jackson: conceptualization, data curation, formal analysis, investigation, methodology, and roles/writing - original draft. Margaret Littlejohn: formal analysis, software, and writing - review and editing. Ed Gane: project administration and writing - review and editing. Stephen Locarnini: writing - review and editing.

\section{References}

1 Rizzetto M. Hepatitis D: thirty years after. J Hepatol. 2009;50(5):1043-50.

2 Wranke A, Pinheiro Borzacov LM, Parana R, Lobato C, Hamid S, Ceausu E, et al. Clinical and virological heterogeneity of hepatitis delta in different regions world-wide: the hepatitis delta international network (HDIN). Liver Int. 2018;38(5):842-50.

3 Deny P, Drugan C, Gatherer D, Campbell Kay A, Le Gal F, Drugan T, editors. Hepatitis D. Virology, management and methodology. Rome, Italy: Il Pensiero Scientifico Editore; 2019. p. $49-80$.
4 Miao Z, Zhang S, Ou X, Li S, Ma Z, Wang W, et al. Estimating the global prevalence, disease progression, and clinical outcome of hepatitis delta virus infection. J Infect Dis. 2020; 221(10):1677-87.

5 Chen HY, Shen DT, Ji DZ, Han PC, Zhang WM, Ma JF, et al. Prevalence and burden of hepatitis D virus infection in the global population: a systematic review and meta-analysis. Gut. 2019 Mar;68(3):512-21.
6 Miao Z, Zhang S, Ou X, Li S, Ma Z, Wang W, et al. Estimating the global prevalence, disease progression and clinical outcome of hepatitis delta virus infection. J Infect Dis. 2020 Apr 27; 221(10):1677-87.

7 Koh C, Da BL, Glenn JS. HBV/HDV coinfection: a challenge for therapeutics. Clin Liver Dis. 2019;23(3):557-72.

8 Koh C, Heller T, Glenn JS. Pathogenesis of and new therapies for hepatitis D. Gastroenterology. 2019;156(2):461-e1. 
9 Palom A, Rodríguez-Tajes S, Navascués CA, García-Samaniego J, Riveiro-Barciela M, Lens $\mathrm{S}$, et al. Long-term clinical outcomes in patients with chronic hepatitis delta: the role of persistent viraemia. Aliment Pharmacol Ther. 2020;51(1):158-66.

10 Jackson K, MacLachlan J, Cowie B, Locarnini S, Bowden DS, Higgins N, et al. Epidemiology and phylogenetic analysis of hepatitis $\mathrm{D}$ virus infection in Australia. Intern Med J. 2018; 48(11):1308-17.

11 Mentha N, Clément S, Negro F, Alfaiate D. A review on hepatitis $D$ : from virology to new therapies. J Adv Res. 2019;17:3-15.

12 Deterding K, Wedemeyer H. Beyond pegylated interferon-alpha: new treatments for hepatitis delta. AIDS Rev. 2019;21(3):126-34.

13 Rizzetto M. Targeting hepatitis D. Semin Liver Dis. 2018;38(1):66-72.

14 Han M, Littlejohn M, Yuen L, Edwards R, Devi U, Bowden S, et al. Molecular epidemiology of hepatitis delta virus in the Western $\mathrm{Pa}$ cific region. J Clin Virol. 2014;61(1):34-9.

15 Jackson K, Tekoaua R, Holgate T, Edwards R, Yuen L, Lee A, et al. Hepatitis B and D in the Pacific Islands of Kiribati. J Clin Virol. 2020; 129:104527.

16 Tsatsralt-Od B. Viral hepatitis in mongolia: past, present, and future. Euroasian J Hepatogastroenterol. 2016 Jan-Jun;6(1):56-8.

17 Rizzetto M. Hepatitis D: thirty years after. J Hepatol. 2009;50(5):1043.

18 Deny P. Hepatitis delta virus genetic variability: from genotypes I, II, III to eight major clades? Curr Top Microbiol Immunol. 2006; 307:151-71.

19 Ramirez AM, Lee SP, Woodfield DG. Hepatitis delta virus infection: a recently imported disease in New Zealand. N Z Med J. 1987; 100(822):235-7.
20 Woodfield G. Hepatitis in the South Pacific. Viral Hepatitis Liver Dis. 1994;3:387-9.

21 Gust I. Epidemiology of viral hepatitis. In: Vyas GN, Dienstag JL, Hoofnagle JH, editors. Viral hepatitis and liver disease. Orlando, FL: Grune and Stratton; 1984. p. 415-21.

22 Jackson K, MacLachlan J, Cowie B, Locarnini S, Bowden S, Higgins N, et al. Epidemiology and phylogenetic analysis of hepatitis $\mathrm{D}$ virus infection in australia. Intern Med J. 2018; 48(11):1308-17.

23 Benson DA, Karsch-Mizrachi I, Lipman DJ Ostell J, Wheeler DL. Genbank. Nucleic Acids Res. 2005;33:D34-38.

24 Katoh K, Standley DM. Mafft multiple sequence alignment software version 7: improvements in performance and usability. Mol Biol Evol. 2013;30(4):772-80.

25 Hall TA. BioEdit: a user-friendly biological sequence alignment editor and analysis program for windows 95/98/NT. Nucl Acids Symp Ser. 1999;41:4.

26 Tamura K, Peterson D, Peterson N, Stecher G, Nei M, Kumar S. Mega5: molecular evolutionary genetics analysis using maximum likelihood, evolutionary distance, and maximum parsimony methods. Mol Biol Evol. 2011;28(10):2731-9.

27 Howell J, Pedrana A, Cowie BC, Doyle J, Getahun A, Ward J, et al. Aiming for the elimination of viral hepatitis in australia, new zealand, and the Pacific Islands and territories: where are we now and barriers to meeting world health organization targets by 2030 . J Gastroenterol Hepatol. 2019;34(1):40-8.

28 Tibbs CJ. Delta hepatitis in Kiribati: a Pacific focus. J Med Virol. 1989;29(2):130-2.

29 Hughes SA, Wedemeyer H, Harrison PM. Hepatitis delta virus. Lancet. 2011;378(9785): 73-85.
30 Noureddin M, Gish R. Hepatitis delta: epidemiology, diagnosis and management 36 years after discovery. Curr Gastroenterol Rep. 2014;16(1):365.

31 Speed BR, Dimitrakakis M, Thoma K, Gust ID. Control of HBV and HDV infection in an isolated Pacific Island: 1. Pattern of infection. J Med Virol. 1989;29(1):13-9.

32 Dimitrakakis M, Gust I. Hdv infection in the western pacific region. Prog Clin Biol Res. 1991;364:89-96.

33 Chao YC, Chang MF, Gust I, Lai MM. Sequence conservation and divergence of hepatitis delta virus RNA. Virology. 1990;178(2): 384-92.

34 Brindle RJ, Eglin RP, Parsons AJ, Hill AV, Selkon JB. HTLV-1, HIV-1, hepatitis B and hepatitis delta in the Pacific and South-East Asia: a serological survey. Epidemiol Infect. 1988; 100(1):153-6.

35 Ifeorah IM, Bakarey AS, Adeniji JA, Onyemelukwe FN. Seroprevalence of hepatitis B and delta viruses among HIV-infected population attending anti-retroviral clinic in selected health facilities in Abuja, Nigeria. J Immunoassay Immunochem. 2017;38:1-12.

36 Katwesigye E, Seremba E, Semitala F, Ocama P. Low sero-prevalence of hepatitis delta antibodies in HIV/hepatitis B co-infected patients attending an urban hiv clinic in uganda. Afr Health Sci. 2016;16(4):1089-93.

37 Safaie P, Razeghi S, Rouster SD, Privitera I, Sherman KE. Hepatitis D diagnostics: utilization and testing in the united states. Virus Res. 2018;250:114-7.

38 Bogomolov P, Alexandrov A, Voronkova N, Macievich M, Kokina K, Petrachenkova M, et al. Treatment of chronic hepatitis D with the entry inhibitor myrcludex B: first results of a phase $\mathrm{Ib} /$ IIa study. J Hepatol. 2016;65(3):490-8. 